\title{
THE IMPLEMENTATION OF FAMILY PLANNING PROGRAMMES
}

\author{
D. M. POTTS \\ International Planned Parenthood Federation, \\ 18-20 Lower Regent Street, London SW 1 4PW
}

World-wide interest in family planning only arose in the latter half of the 1960s and remains small in comparison to the need. The United States Government, for long the largest donor to international family planning, gave, in 1965, a sum of money equivalent to the cost of seven modern tanks, in 1966 the equivalent to seven helicopters and in 1967 to one B52 bomber (Stycos, 1971). Now it is at a rate that will buy one modern aircraft carrier in 10 years. Currently the IPPF is spending each year slightly more than the inhabitants of the United Kingdom invest in backing horses on Derby Day. Rich and poor countries together spend more on colour films for cameras than they do on contraceptives.

Unhappily, family planning programmes have not been structured to work within the real constraints set upon them. Some services in the United States spend as much on recruiting and looking after one family planning acceptor for 1 year as the per capita income of a poor country. In the developing world, programmes are sometimes exclusively tied to health services, which are themselves inadequate for the heavy burden of preventive and curative medicine which they must carry and may be culturally inappropriate. Doctors often prove poor planners and advisers and this defect, combined with the vagaries of legislation and the biases of politicians, has led to odd paradoxes.

The conventional ideal family planning programme is spelt out by Michanek (1971) in a humane but bold plan for world development. Criticizing UN plans for the 1970s for under-emphasizing the problem of population increase he goes on, 'The UN strategy should have specified that its implementation in fact will depend on: the ability of hundreds of family-planning programmes to find qualified leaders; the equipping of thousands of clinics; the recruiting, training and placing of hundreds of thousands of employees; the provision of information and service to hundreds of millions of couples; the prevention of many millions of births during the next four decades; the spending of billions of dollars for this work'.

Excellent as these ideas are, will they be followed?

LIMITATIONS

\section{Personnel}

The ratio of people to doctors is very high in all developing countries (Table 1). Doctors are concentrated in urban areas, usually disproportionately in the capital 
city. With rare exceptions, doctors are not found living beside the rural populations that make up the great bulk of the world's numbers. The odds are heavily stacked against the villager ever receiving individual treatment from a qualified doctor, or other trained health personnel.

Table 1. Population in relation to the numbers of health personnel

\begin{tabular}{l|c|c|c}
\hline \multirow{2}{*}{ Country } & \multicolumn{3}{|c}{ Population in thousands per: } \\
\cline { 2 - 4 } & doctor & midwife & nurse \\
\hline Korea & & & \\
Iran & $2 \cdot 4$ & $5 \cdot 0$ & $3 \cdot 2$ \\
Morocco & $12 \cdot 8$ & $18 \cdot 3$ & $8 \cdot 2$ \\
Indonesia & $27 \cdot 6$ & $86 \cdot 0$ & $4 \cdot 5$ \\
India & $4 \cdot 8$ & $19 \cdot 8$ & $5 \cdot 3$ \\
Ghana & $13 \cdot 3$ & NA & $9 \cdot 6$ \\
\hline
\end{tabular}

Modified from Nortman (1972).

Doctors command approximately the same range of salaries all over the world, so that their professional time becomes relatively more expensive in developing countries. A doctor represents a large capital investment, usually exceeding $£ 30,000$, and is a piece of equipment with very high running costs. Many governments, not able to afford to pay the high salaries which doctors command, must either compel doctors to work for them or see their medical services understaffed. Given a free choice, doctors often opt out of government services as soon as possible. The goal of many doctors in the developing world is to establish a private practice. In Taiwan, $70 \%$ of medical manpower is devoted to private practice (Baker \& Perlman, 1967), in India somewhere between 40 and 70\% (depending on the state concerned) and in Malaya over 60\%. As a consequence government vacancies go unfilled, including those in family planning programmes.

The situation with non-doctor health personnel is similar and sometimes even more acute. In India, Egypt and many other countries, the number of doctors exceeds the number of fully qualified nurses and midwives. Nurses and midwives are also eager to practice in urban areas: differentials in salary may not be as great as in the case of doctors but the opportunities for marriage and social activity provide a strong stimulus for urban living.

The international migration of medical skills further deprives services of manpower. 'The world now provides as much or more medical aid to the United States in terms of dollars as the total cost of all American medical aid, private and public, to foreign countries' (Titmuss, 1968). Two thousand three hundred Pakistani doctors left their country in the early 1960s, representing half the output of trained doctors, and most came to work in the United Kingdom. The number of Indian doctors who are working abroad, again many in the United Kingdom, is equivalent to the number employed in the rural health services of their native country. 


\section{Economic}

Developing countries devote relatively less of their gross national product on health care than rich nations and many spend less than one dollar US/person/year on all aspects of health care (Table 2). For a sum of money as small as a few cents a year a significant decline in the death rate appears to be achievable.

Table 2. Health expenditure in selected countries

\begin{tabular}{l|c|c}
\hline Country & $\begin{array}{c}\text { Proportion of GNP } \\
\text { spent on health } \\
(\%)\end{array}$ & $\begin{array}{c}\text { Per capita health } \\
\text { expenditure } \\
(\$)\end{array}$ \\
\hline U.S.A. & 5.7 & 162.00 \\
U.K. & 3.85 & 56.00 \\
Jamaica & 2.1 & 9.60 \\
Thailand & 0.5 & 0.65 \\
Ethiopia & 1.35 & 0.72 \\
\hline
\end{tabular}

After Fendall (1972).

It is reasonable to argue that the sum of money available for family planning should be increased in nearly all countries. It is difficult to argue, however, that family planning budgets should consume a sum of money equal to or greater than that spent on health services. In 1956-57, India was spending over 7000 rupees $(\$ 1000)$ per birth averted; in $1958-59$, this figure fell to R700 (\$100) and is now at the R200 mark ( $\$ 30)$. Even current expenditure is equivalent to 4 months' income for the average Indian.

\section{Cultural}

Perhaps the ultimate tragedy of the translation of western medical practice into the peasant communities of developing countries is not the lack of resources which make it impossible to provide a meaningful service, nor that the trained staff are unwilling to work in the villages, but that the community itself may be bewildered or even antagonistic towards the service offered. Egypt, because of its excellent communications and its high density of population on a narrow strip of cultivated land, has a better infrastructure of health facilities than other comparable countries. It trains a large number of doctors through a much expanded university system. Nevertheless, when clinics, doctors and nurses are all available, services can remain under-utilized, even in situations where the need is obvious. The maternal mortality rate remains high and one or two women a year may die in a village with a population of a few thousand. Infant mortality is well over $100 / 1000$, that is, five to six times that in the United Kingdom. Yet, the available obstetric beds at the village level lie unused and available skills are not called upon. The women continue to turn to the traditional midwife or 'daya'. Officially illegal, always untutored and irregularly defined, the daya continues to compete with a service which is available free of charge to women who care to walk across the village to get it. These problems are intrinsic in the introduction of health services and it is no criticism of these services that they have not been overcome. However, they must be recognized 
because family planning, above all other activities, is likely to be most sensitive to cultural barriers between those who serve and those served.

\section{THE LINK WITH HEALTH SERVICES}

Nortman (1972) has written, 'thus far programmes have been structural so that family planning is a by-product of health services, and not health improvements a by-product of family planning'.

The family planning clinic system is very expensive, and mobile clinics (which have been tried in areas especially deficient in medical services) are most expensive of all. At fixed clinics in Venezuela, physicians see an average of 0.5 to 1.9 new patients/hour. In Brazil, they see 0.2 to 2.4 . This is a slower rate of turnover than a consultant in the National Health Service seeing outpatients, faced with a great variety of diseases and having to make decisions upon which a patient's life may depend. In developing countries, the average doctor at a hospital outpatients clinic might see several hundred patients a day. Even if these low rates of family planning clinic turnover were excusable, they could not be afforded. There are 20,000 doctors in Brazil: if 1000 of them spent $4 \mathrm{hr} /$ day (a gross overestimate of the resources ever likely to be available) they would see one or two million new patients a year, one in twenty of all fertile women. Within existing clinics, there has been considerable opposition to any delegation of duties to non-physicians. Women are often made to return to clinics with excessive frequency. Sometimes they are seen monthly and the return visits, as well as the initial interview and examination, may be performed by doctors. When it is recalled that, in many developing countries, the average woman may not visit a doctor throughout her life, this disproportionate 'care' probably generates apprehension in those it is designed to help. If the woman must visit a doctor to obtain oral contraceptives she is likely to infer that the therapy must be a very dangerous one or society would not devote the expensive services of a physician to its distribution.

Doctors rarely analyse the most efficient and effective use of their skills, although this type of analysis is as necessary as the investigation of pharmacological properties of a new drug. An insidious form of medical colonialism has occurred throughout the world as patterns of western medicine have been adopted for developing societies. In many ways, family planning clinics are part of the philosophy of hospital-based medicine: a quality service for a minority sometimes conducted at the expense of the majority. Hospital-based medicine has run riot in many countries, bringing much less reward to the community than the investment which has been made in it. In one African country, a fine new hospital building stands empty because, when it had been built by a generous donor government, it was discovered that the salaries of the doctors necessary to staff it would take an intolerable slice from the limited health budget of that country, which has over 20 million people and a per capita income of $\$ 5$ a month.

In Senegal in the early 1960s a single new hospital in St Louis absorbed half the funds set aside for health and twice the sum devoted to the care of the rural communities throughout the entire country where most of the country's 3.5 million population live.

Basically, in nearly all aspects of health care, personnel time is more expensive 
than drugs and appliances. This alone should justify scientific analysis of alternative patterns of care.

There are many gaps in our knowledge about the logistics of curative medicine. It is not even clear whether it is better to conduct a normal delivery at home or in hospital although there are numerous passionate statements on this topic (Cochrane, 1972). In family planning the situation is worse. The rôle of the traditional family planning clinic has never been analysed in any randomized clinical trial of effectiveness. There is no study to assess different forms of supervision of oral contraceptives. There is an almost unshakable belief that doctors do something useful when supervising the distribution of the pill and an impression that it is unethical to suggest alternative systems. The reverse way of posing the problem, that it is unethical to use the skills of a doctor unless the use of such skills can be rigorously justified, rarely seems to occur.

In many situations, particularly Latin America, there is pressure to include taking cervical smears into the work of family planning clinics, although the provision of such services in developing countries approximately doubles the cost of a family planning programme. As Cochrane (1972) has pointed out, 'no convincing evidence has been published of a greater fall of this (carcinoma of the cervix) death rate in areas where there has been a high coverage of the female population when compared with similar areas where little such work has been done'.

THE IMPACT OF FAMILY PLANNING

The analysis of the demographic effects of family planning programmes is exceptionally difficult. In countries such as Singapore and South Korea there appears to be evidence that the birth rate has fallen at a time of vigorous public family planning programmes. But, in the giant populous countries of the world, such as India and Indonesia, there is to date no evidence of any demographic impact from the effort that has been expended in the field of family planning. When India began its national family planning programme the growth in population of the country was approximately 5 million a year; now, after two decades of considerable effort (in relation to the limited resources of the country), the rate of population growth is approximately 13 million/annum. In all developing countries, the population pyramid is highly distorted by an excessive number of young people and often more than $40 \%$ of the population may be below the age of puberty. Every year a great many young fertile women enter the 15 to 45 age group, while relatively few leave it by death or reaching the menopause. To return to the problem of resources in Brazil, if, on the generous assumption made about the use of medical manpower in that country which might be diverted into family planning programme, 2 to 3 million women a year could be given contraceptive advice through medically based services, then more than half this number would be taken up by the annual addition of women to the fertile years. Even the best programme that could be mounted would barely keep pace with an ever growing problem. It is statistics of this type which must force a serious re-appraisal of the current implementation of family planning programmes. 


\section{MISTAKES AND OMISSIONS}

We are beginning to learn how the cultural acceptability of a technique and the logistics of providing a service interact. Vasectomy is an example of the relationship between these two variables. Technically, it is a simple operation which can be done as an outpatient procedure by a surgeon of only moderate training, and the attendant complications are rarely serious or immediate. It does appear possible to make vasectomy available with the limited medical resources found in many countries. There is no surgical reason why vasectomy should not have been used in Britain since the 1870s and there is sociological evidence that it would have been widely acceptable (Deys, 1973). It has become popular at the present time, not because the needs of couples are changing, but because medical attitudes are evolving. Vasectomy is widely practised in India, South Korea, Pakistan and the Peoples' Republic of China and is beginning to be made available in other countries, including parts of Latin America. However, in some countries with great national family planning programmes such as Indonesia, Turkey or Egypt, it has not been made available and their programmes are the poorer.

Female sterilization is an example of a birth control technique where the ratelimiting factor concerning its use is the availability of medical skills. The operation usually requires a general anaesthetic, a period in hospital and always needs a surgeon with a higher degree of specialization than is the case of male sterilization.

The list of arbitrary omissions of valid methods of birth control available from family planning clinics in various countries is long and full of paradoxes. In Japan, abortion is readily available, but IUDs and pills are illegal; in England, sterilization is moderately freely available, but abortion subject to great debate; in Sweden and Yugoslavia, abortion is readily acceptable, but vasectomy remains illegal; in some states in America, abortion is available at the request of the woman, in others, people have gone to prison for handing out contraceptives; in India, tens of thousands of men have been sterilized within a few weeks in a giant vasectomy campus, but nowhere in the country are oral contraceptives made available in a realistic way. The only country that makes all birth control methods available to the community of potential users is mainland China (Potts, 1972).

\section{NEW OPTIONS}

\section{Commercial distribution}

Alternative channels to physician-based care exist in nearly all countries. At first sight they may appear unsatisfactory, but on closer examination have much to offer family planning. Prentice (1963) describes the 'amazing variety of ancient and ineffective drugs' imported into developing countries. In Taiwan, there are four times as many drug stores per head of the population as in the United States. Myrdal (1963) writes that 'as indigenous medicines are not subject to control in India, rejected modern drugs can be easily marketed in their guise. In many communities the pharmacist has come to stand in the stead 
of the doctor who is not available or too expensive for most of the population'. Mauritius spends a higher proportion of its national income on drugs than the United Kingdom (Titmuss, 1968).

The commercial distribution of contraceptives is poorly developed, and indeed barriers remain to their distribution in many places. Some countries with national programmes maintain tariffs against the importation of contraceptives. In Ceylon, the government favours family planning but will not permit the advertising of condoms in the media it controls. Despite these problems an estimated $40 \%$ of contraceptives used in developing countries are sold commercially (Sollins \& Belsky, 1970). A great deal could be done to increase further the sale of condoms and spermicides (Black \& Harvey, 1972).

De facto, a non-medically supervised commercial distribution of oral contraceptives is available to the middle classes who can afford them in nearly all developing countries. However, only a minority of nations, such as South Korea and Fiji, legally acknowledge this trade. For the rest, the villager and the slum dweller can get subsidized pills from doctors working for national programmes, where, as mentioned, doctors are in short supply and the method of distribution may make oral contraceptives culturally unacceptable. There is now a movement to re-think the whole necessity for medical supervision of pill distribution and there has recently been a suggestion in the United Kingdom that 'progesterone-only' pills might be made available without prescription in this country. Some people have also asked the question, what would happen to the data of female morbidity and mortality due both to childbirth and the control of fertility, if pills were made more widely available and prescription was no longer mandatory.

Sound decisions must be made upon an epidemiological basis but it is not unreasonable to point out that, in many developing countries, patients often buy other types of pills one at a time, or borrow money to obtain what may be inappropriate, adulterated, and potentially dangerous drugs. They may be misused not only from the point of view of the individual but from the point of view of the community as a whole, as when antibiotic resistance develops. Amidst these problems oral contraceptives stand out as drugs difficult to abuse. Misuse mainly results in the patient relapsing to the previous condition of being at risk for pregnancy. They are not addictive, you cannot build up a resistance to them and an overdose is not lethal.

\section{Sterilization and abortion}

Family planners have given themselves an unobtainable goal by trying to control fertility using reversible methods of contraception alone. Sterilization has a real place in family planning programmes, not only because of its convenience but because the reversible methods of fertility control currently in use are not adequate to allow a cross-section of any population to control its fertility within the goals of family size now acceptable in industrialized nations-and hoped for in many developing countries. If 20 years of exposure to pregnancy is assumed and three children planned, then, with using an effective method of contraception, such as the condom or diaphragm, 30 to $35 \%$ of women can expect to 
have one unplanned pregnancy, 46 to $56 \%$ two or more unplanned pregnancies, and only 13 to $18 \%$ will not exceed their desired family size (Hulka, 1969). This hypothetical model fits with sociological studies. In the United States, Westhoff \& Ryder (1970) showed that one-third of couples interviewed admitted that they had already had at least one unwanted pregnancy, even though, at the time the sample was taken, the women had not reached the end of their fertile years. Potter (1971) has analysed the limitations of one-method approaches to fertility control in Taiwan.

The alternative to sterilization is to use contraceptive methods backed up with induced abortion if they fail. The two options are not exclusive and probably all societies would benefit from access to both.

The inclusion of abortion services in birth control programmes has certain additional advantages. It widens the options for reversible methods of contraception. In biological terms, it seems reasonable to argue that the more effective a hormonally based contraceptive is in preventing pregnancies the greater is likely to be the number of side effects. (Incidentally, the availability of abortion on request would greatly accelerate the screening of new contraceptive methods with the help of volunteers who understood both the nature of the trial and the possibility of having their pregnancy terminated should the method fail.) There is evidence that the greater the bulk of an intra-uterine device the lower the pregnancy rate, but the greater the side effects. It is possible that if decisions were made to use certain methods of contraception which might have a higher pregnancy rate than some already in use, but fewer side effects, then continuation rates might be improved and overall there could be fewer unwanted pregnancies and less abortions in the community. The nettle that has to be grasped is the need to guarantee access to abortion should pregnancy occur and the woman wish it.

It can also be shown that there is marginally less risk to the couple concerned if a simple method of contraception, such as the condom or even coitus interruptus, is used to space out pregnancies, and unwanted pregnancies are terminated, than in using more sophisticated methods of contraception such as oral contraceptives, which carry a tiny but measurable risk to life. Probably this fact is of merely academic interest, as the aesthetics of the situation nearly always outweigh the small risks involved.

The single most important advantage of the availability of abortion within birth control services would be a great improvement in credibility: couples appear to make a decision to control their fertility and to implement this decision in whatever way is necessary, rather than to decide to use a particular method of family planning. Contraceptives become more acceptable when backed up by abortion. The performance of legal abortion makes those women with unwanted pregnancies accessible to contraceptive advice.

Unlike sterilization, abortion will be embarked upon illegally even in the absence of professional advice. For example, careful surveys in Santiago, Chile, suggest that in that one city (which has only one-quarter of the population of London) there are half as many illegal abortions a year as there are legal abortions in England and Wales. The conflict between public belief and private practice is stronger in the case of abortion than sterilization, although some 
might feel it presents slightly less weighty ethical problems. Despite cost and possible danger to the woman concerned it has been shown from South America that those who have had one illegal abortion are more likely than others to have a second one. Those cultural groups which reject the procedure most vociferously sometimes seem to resort to it with above average frequency (Ingram \& Sims, 1972).

The logistics of providing an adequate legal abortion service have been carried forward in past years and are probably applicable to nearly all countries both rich and poor. The experience of Berić \& Kupresanin (1971) in northern Yugoslavia over a number of years has shown that outpatient abortion can be safe and quick and, with an opportunity to provide a long-term follow-up of the women involved, it shows a relatively low morbidity. Of 22,909 they reported thirteen perforations at the time of operation, an average blood loss of well under $200 \mathrm{ml}$ and no deaths. Nathanson (1972), in the United States, has reported on 28,000 consecutive abortions with a minimum of complications (Table 3) although the experience is recent and long-term follow-up in the

Table 3. Out-patient abortion complications resulting from 29,696 operations (July 1970 to August 1971) (from Nathanson, 1972)

\begin{tabular}{l|r|c}
\hline \multicolumn{1}{c|}{ Nature of complication } & No. & Rate per thousand \\
\hline No. of deaths & 0 & - \\
Known perforations & 36 & $1 \cdot 4$ \\
Laparotomies & 13 & - \\
Hysterectomies & 1 & - \\
Repeat curettage & 90 & $3 \cdot 5$ \\
Infections* & 391 & $15 \cdot 0$ \\
Patients admitted to hospital & 49 & - \\
with infections & 54 & $2 \cdot 1$ \\
Taemorrhage & 634 & 22 \\
\hline
\end{tabular}

* Temperature $38^{\circ} \mathrm{C}$ on 2 successive days, exclusive of first $24 \mathrm{hr}$.

United States, for a series of valid social reasons, is poor. Nathanson's terminations were performed in a clinic which handles about 100 operations a day as outpatient procedures, often on women who have travelled half-way across a continent. A single centre of this type can perform 30,000 or more operations a year and this is a significant number even in the context of developing countries. Two centres of this type could perform all the non-National Health Service operations that take place in the United Kingdom. The facilities involved are two floors of an office block, a small number of permanent staff, a larger number of sessional doctors (who would be available in the urban areas of any developing country) and a number of counsellors, who prepare the women for an operation which still presents a number of emotional problems and which needs to be well understood if it is to be carried out under local anaesthesia. 


\section{CONGLUSIONS AND STRATEGY}

There was a diplomatic joke at the time of the unhappy conflict in Cyprus that anyone who thought he had the solution to the situation was wrong! There is certainly no single solution of the difficult problem for fertility control for the individual or society. The first prerequisite of any strategy must be flexibility so that ultimately the community itself can determine the exact shape of any family planning programme.

There is need to make reversible methods available either commercially at a price that is meaningful to the community or free of charge. Condoms and spermicides should be domestic items obtained with the same ease as the family gets it vegetables. Clinics are important but their rôle needs to be redefined. They should be mainly places for consultation for couples who find difficulty in controlling their fertility, or who particularly want the quality service because it gives them a degree of reassurance. Clinics should take the leadership within the locality that they serve, should be aware of its problems and be able to identify and help groups at a special risk. New ways of distributing oral contraceptives need to be developed. Duties need to be delegated; the armies of field workers now involved in some family planning programme must carry contraceptives with them. Intra-uterine devices are likely to remain limited in their use because of a lack of trained persons for insertion and follow-up, although it has been demonstrated that such a person need not be medically qualified.

The strategy for doctors should be to withdraw from the distribution of reversible methods of contraception (with the exception of using their status within society as powerful motivators) and to concentrate upon sterilization, induced abortion and advice on that small minority of Pill and IUD users who present more than usual difficulties.

\section{REFERENCES}

Baker, T. D. \& Perlman, M. (1967) Health Manpower in a Developing Economy: Taiwan, a Case Study in Planning. Johns Hopkins University Press, Baltimore.

Berić, B. M. \& Kupresanin, M. (1971) Vacuum aspiration, using pericervical block, for legal abortion as an outpatient procedure up to the 12 th week of pregnancy. Lancet, ii, 619 .

BlACK, T. R. L. \& HARvey, P. O. (1972) Commercial distribution of contraceptives: a non-medical supplement to the family planning effort. In New Concepts in Contraception. Eds. M. Potts and C. Wood. MTP, Oxford and Lancaster.

Cochrane, A. C. (1972) Effectiveness and Efficiency. Random Reflections on Health Services. The Nuffield Provincial Hospital Trust, Oxford.

Deys, C. M. (1973) Cultural aspects of vasectomy. Aust. N.Z.J. Obstet. Gynaec. (in press).

Fendall, N. R. E. (1972) Medical care in developing nations. In International Medical Care. Eds. J. Fry and W. A. Farndale. MTP, Oxford and Lancaster.

Hulka, J. F. (1969) A mathematical model study of contraceptive efficiency and unplanned pregnancies. Am. J. Obstet. Gynec. 104, 443.

INGRAM, C. \& Sims, M. (1972) Study of applicants for abortion at the Royal Northern Hospital, London. 7. biosoc. Sci. 4, 351 .

Michanek, E. (1971) The World Development Plan. A Swedish Perspective. Almquist \& Wiksell, Stockholm. Mrrdal, G. (1963) Asian Drama. Penguin Press, London.

Nathanson, B. M. (1972) Ambulatory abortion experience with 26,000 cases. New Engl. 7. Med. 286, 403.

Nortman, D. (1972) Status of national family planning programmes of developing countries in relation to demographic targets, Popul. Stud. 26, 5.

Potter, R. G. (1971) Inadequacy of a one-method family planning program. Stud. Fam. Plann. $2,1$. 
Potrs, D. M. (1972) Models for progress: United Kingdom (1919-1939) and China People's Republic (1957-1971). In New Concepts in Contraception. Eds. M. Potts and C. Wood. MTP, Oxford and Lancaster.

Prentice, C. R. M. (1963) Land of a million elephants. Lancet, ii, 289.

Sollins, A. D. \& BELSKY, R. L. (1970) Commercial production and distribution of contraceptives. Reports on Population/Family Planning, $4,1$.

STYcos, J. M. (1971) Ideology, Faith and Family Planning in Latin America. McGraw-Hill, New York.

Trтmuss, R. M. (1968) Commitment to Welfare. Allen \& Unwin, London.

Westofr, G. F. \& RyDer, N. B. (1970) Family Limitation in the United States. Int. Population Conf., London 1969. Vol. 2, p. 1174. IUSSP, Liège. 